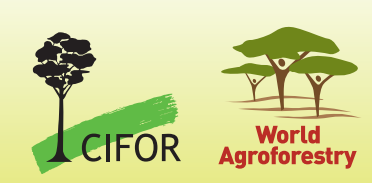

\title{
Percibir, sentir, pensar \\ Por qué el cuerpo, el corazón y la mente son importantes para la gestión de los ecosistemas
}

\author{
Emilia Pramova', Bruno Locatelli2,1 y Merelyn Valdivia-Díaz ${ }^{3}$
}

\section{Mensajes clave}

- Las personas valoran los ecosistemas debido a las diferentes contribuciones que estos hacen al bienestar humano, tanto material como inmaterial.

- Las contribuciones no materiales, como aquellas relacionadas con la identidad, el sentido del lugar y el bienestar psicológico, tienen dimensiones afectivas, cognitivas y sensoriales.

- Aunque suelen ser pasados por alto en la gestión e investigación de los ecosistemas, los aspectos afectivos y sensoriales son importantes para la conexión con la naturaleza, el bienestar humano, la conservación y la justicia ambiental.

- Este informe resume los principales hallazgos de la investigación cualitativa realizada en Apurímac (Perú) que explora las dimensiones afectiva, cognitiva y sensorial de las experiencias e inspiraciones de las personas sobre los ecosistemas.

- Comprender la diversidad de experiencias e imaginarios de las personas es importante para una gestión de los ecosistemas más equitativa y sostenible.

\begin{abstract}
"Cuando cantaban con sus voces delgaditas, otro paisaje presentíamos; el ruido de las hojas grandes, el brillo de las cascadas que saltan entre arbustos y flores blancas de cactus, la lluvia pesada y tranquila que gotea sobre los campos de caña; las quebradas en que arden las flores del pisonay, llenas de hormigas rojas y de insectos voraces".
\end{abstract}

en Los ríos profundos de José María Arguedas (1911-1969), novelista, poeta y antropólogo de Apurímac, Perú.

\section{Relación con los ecosistemas}

Los ecosistemas contribuyen al bienestar humano de diversas formas. Proporcionan alimentos, madera y otros materiales, regulan el agua y el clima y protegen a las personas de diferentes peligros. Las contribuciones no

\footnotetext{
1 CIFOR

2 CIRAD, Bosques y Sociedades, Universidad de Montpellier

3 UNALM, Universidad Nacional Agraria La Molina
}

materiales, como las relacionadas con la recreación, la espiritualidad, el sentido del lugar y la salud mental, también se conocen como servicios ecosistémicos culturales.

Las personas valoran y gestionan los ecosistemas por sus diversas contribuciones, tanto materiales como no materiales, pero los tomadores de decisiones con frecuencia ignoran estas últimas, quizás porque son difíciles de cuantificar, mapear y monetizar (excepto para el turismo o la recreación). En muchos casos, las contribuciones no materiales, como las relacionadas con la identidad y el sentido del lugar, pueden ser incluso más importantes para las personas que las contribuciones materiales (Elwell et al. 2020). También tienen una poderosa influencia en el comportamiento para la conservación y la motivación.

Otros ejemplos de contribuciones no materiales incluyen el apoyo al sentido de pertenencia, la reducción de la ansiedad, el estímulo de la inspiración, la provisión del deleite visual y la contribución al desarrollo y la 
preservación del conocimiento local. Estas contribuciones están determinadas por las interacciones de las personas con lugares, localidades, ecosistemas y diferentes seres vivos y no vivos, y por la interpretación que hacen de ellos. Por lo tanto, surgen de las interrelaciones entre las personas y los ecosistemas, y las personas construyen valores no materiales en y a través de estas relaciones (Fish et al. 2016).

Las personas desarrollan relaciones con los ecosistemas a través de interacciones y experiencias directas con la naturaleza y el lugar. Estas interacciones y experiencias se dan mediante los sentidos y producen como resultado estados afectivos: emociones y sentimientos. Estas experiencias sensoriales y afectivas también fomentan la conexión con la naturaleza. Esta conexión significa sentirse interrelacionado con el resto de la naturaleza, sentirse parte de ella y tener una fuerte afinidad emocional con el mundo no humano.

Las personas que están conectadas con la naturaleza se preocupan más por el medio ambiente y por lo general tienen sólidas actitudes a favor de la conservación (Zylstra et al. 2014). Un creciente corpus de investigación, en especial en países industrializados y áreas urbanas, también demuestra los muchos efectos beneficiosos de las interacciones sensoriales directas con la naturaleza, tales como un mejor funcionamiento cardiovascular e inmunológico, mejores capacidades cognitivas, mayor satisfacción con la vida, mayor felicidad y vitalidad, y reducción de la ansiedad y la depresión (véase Frumkin et al. 2017 para una revisión completa).

Las dimensiones afectivas y sensoriales de las interacciones entre el ser humano y la naturaleza son importantes para entender los valores no materiales de los ecosistemas y para mejorar la conectividad, el bienestar humano y la conservación. También son importantes para una gestión más ética y justa de los ecosistemas. Pero los investigadores y profesionales preocupados por los ecosistemas y sus contribuciones no materiales se han centrado principalmente en las dimensiones cognitivas (por ejemplo, cómo las personas perciben un entorno, qué preferencias tienen por los paisajes y el panorama, y qué valores asignan a los diferentes componentes del ecosistema) (Mastrángelo et al. 2019).

Con este resumen, esperamos inspirar más sensaciones y emociones en la gestión e investigación de los ecosistemas. Resumimos los mensajes clave y los hallazgos de la investigación cualitativa sobre las experiencias y los imaginarios afectivos, cognitivos y sensoriales relacionados con diferentes paisajes en los Andes peruanos (para más resultados de nuestro estudio, véase Pramova et al. 2021).

\section{Comprender las experiencias y los imaginarios}

Para comprender mejor las experiencias y los imaginarios personales relacionados con paisajes específicos en nuestra área de estudio en los Andes peruanos, realizamos discusiones abiertas a partir de 15 fotografías (figura 1). Hablamos con siete pobladores rurales y siete pobladores urbanos, siete turistas y siete profesionales de instituciones dedicadas a la gestión de los recursos naturales que aceptaron conversar con nosotros luego de un proceso de selección aleatorio. Pedimos a los entrevistados que eligieran cinco imágenes y luego hablaran libremente sobre ellas.

Esta investigación formó parte de un proyecto más amplio que estudia los servicios de los ecosistemas en la cuenca del Mariño en Apurímac, Perú, en especial en relación con la equidad (Vallet et al. 2019) y el poder (Vallet et al. 2020). Al igual que muchas otras áreas montañosas del mundo, nuestra área de estudio es un proveedor clave de varios servicios ecosistémicos (Martín-López et al. 2019) y está sujeta a cambios rápidos en dichos servicios (Locatelli et al. 2017).

Registramos 139 descripciones de las imágenes y analizamos su contenido. Codificamos los fragmentos de texto relevantes en las descripciones, utilizando un marco simple con cinco dimensiones, que cubre las dimensiones afectiva, cognitiva y sensorial, y los escenarios y actividades relacionados (figura 2).

En este marco, los escenarios se refieren a componentes del ecosistema vivos y no vivos (por ejemplo, árboles, montañas), imágenes escénicas de carácter más general (por ejemplo, la inmensidad del paisaje) y elementos más efímeros (por ejemplo, la suave brisa de la mañana, la luz y colores del atardecer). Las actividades se refieren a experiencias físicas, como el senderismo y la natación, pero también a interacciones metafísicas e intelectuales como soñar e imaginar.

Las experiencias sensoriales se relacionan con los cinco sentidos exteroceptivos (vista, oído, olfato, gusto y tacto) y con experiencias vinculadas al movimiento (cinestésicas) y la gravedad, con percepciones formadas por el procesamiento e interpretación de estímulos externos captados por los sentidos. Aunque es difícil determinar dónde termina la percepción y comienza la cognición, para el análisis práctico, consideramos que las experiencias cognitivas son procesos conceptuales y reflexivos como pensar. Suelen implicar valores, actitudes, conocimientos y creencias, e incluyen recuerdos, estética, pensamientos espirituales, nostalgia o inspiración. 


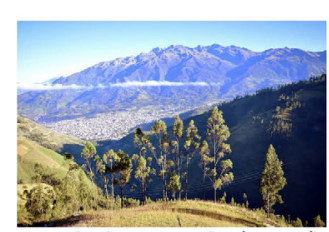

Cuidad y nevado $(n=16)$

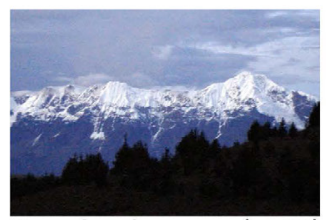

Nevado y bosques $(n=10)$

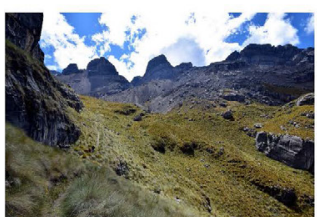

Pastizal de ichu $(n=6)$

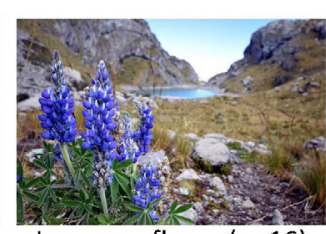

Laguna y flores $(n=16)$

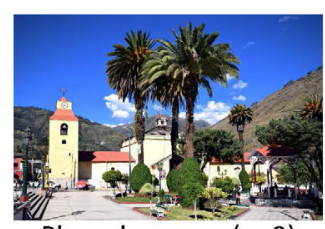

Plaza de armas $(n=9)$

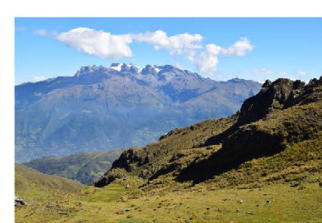

Nevado $(n=4)$
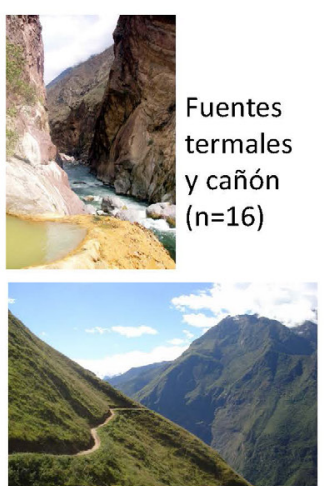

Sendero $(n=9)$

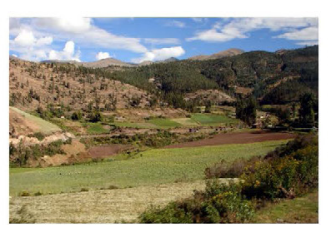

Paisaje rural $(n=4)$

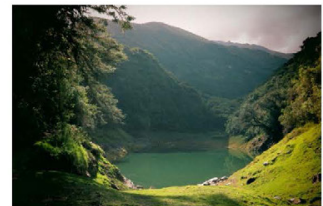

Laguna y bosque $(n=15)$

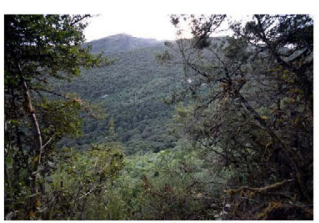

Bosque andino $(n=6)$

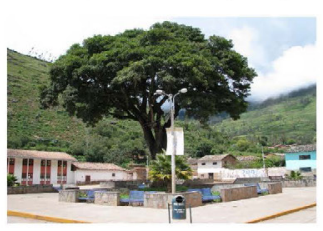

Plaza de pueblo $(n=4)$
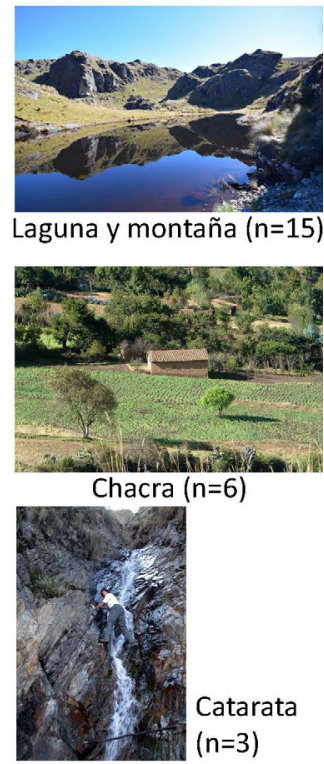

Catarata

$(n=3)$

Figura 1. Las 15 fotografías comentadas por los entrevistados, ordenadas por número decreciente de veces (n) que fueron seleccionadas.

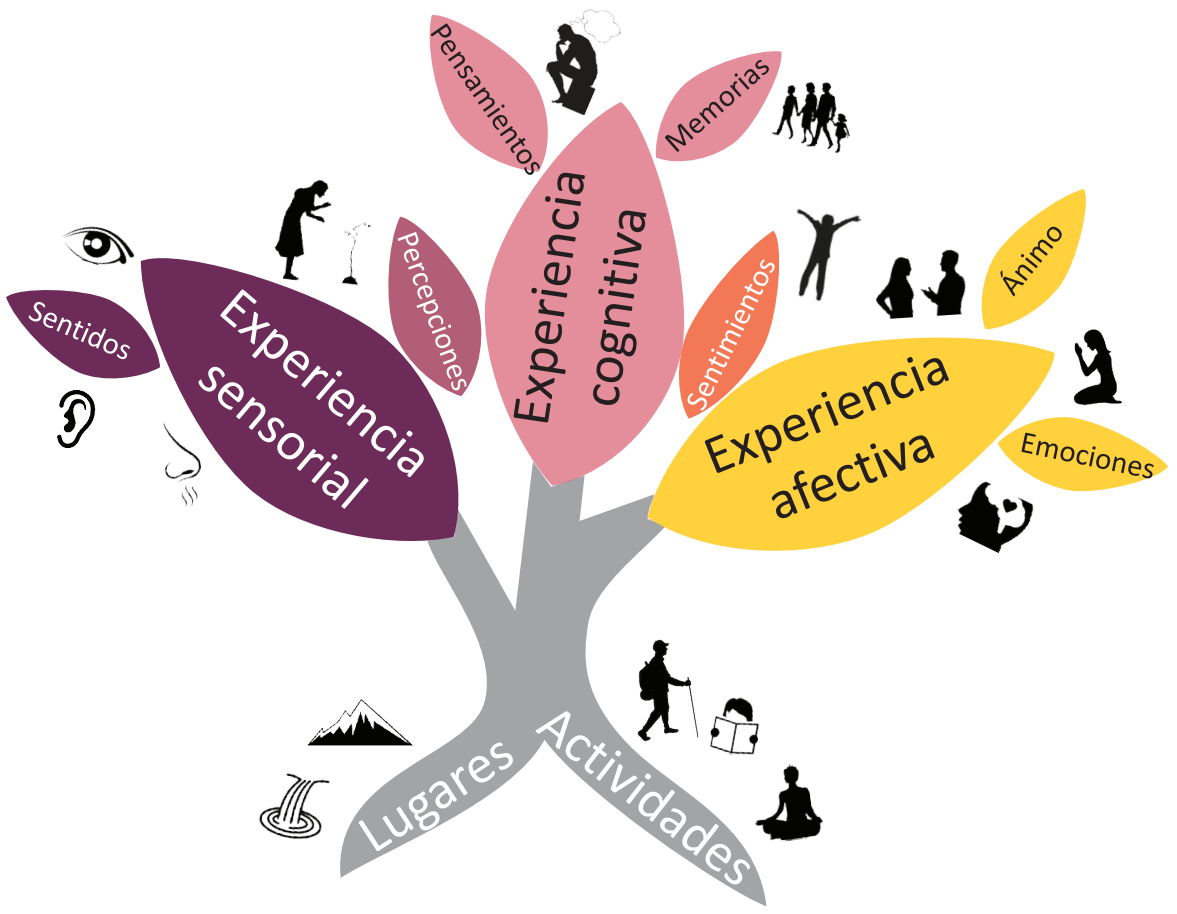

Figura 2. Marco propuesto para el análisis de experiencias personales vividas relacionadas con lugares, ecosistemas o paisajes. 
Las experiencias afectivas incluyen estados de ánimo, sentimientos y emociones a lo largo de una gradiente que va de bueno/agradable a malo/desagradable. Todas las emociones son afectivas, pero no todas las condiciones afectivas son emociones. Consideramos los sentimientos y las emociones como experiencias afectivas, reconociendo que no es práctico distinguirlos. También es importante señalar que la sensación, la emoción y la cognición están integradas en la experiencia y es difícil determinar dónde termina un proceso interno y comienza otro.

\section{Abrirse a la diversidad}

Nuestros entrevistados compartieron diversas narrativas, todas ellas ricas en simbolismo y experiencias sensoriales, emociones y recuerdos personales (tabla 1), que vincularon con creencias generales sobre los seres humanos, los lugares y la naturaleza. Casi todas las descripciones incluyeron por lo menos una mención de un escenario (99\%) o una experiencia cognitiva (96\%). Más de la mitad de las descripciones informaron sobre una experiencia sensorial (60\%) o afectiva (55\%),

Tabla 1. Diversidad dentro de las tres dimensiones de la experiencia en nuestros datos

\begin{tabular}{|c|c|c|}
\hline Dimensión & Subdimensión & Definiciones o ejemplos \\
\hline \multicolumn{3}{|l|}{ Sensorial } \\
\hline & Gravedad & Percibir el espacio y la fuerza de gravedad \\
\hline & Cinestesia & Percibir el movimiento \\
\hline & Vista & Percibir cosas a través de los ojos \\
\hline & Olfato & Percibir aromas y olores a través de la nariz \\
\hline & Sonido & Percibir y el sonido y las vibraciones auditivas a través de los oídos \\
\hline & Tacto & Experimentar sensaciones a través de la piel \\
\hline \multicolumn{3}{|l|}{ Cognitiva } \\
\hline & Estética & Apreciar la belleza de la naturaleza \\
\hline & $\begin{array}{l}\text { Preocupación por la } \\
\text { naturaleza }\end{array}$ & Valorar la protección y el bienestar que brinda la naturaleza \\
\hline & $\begin{array}{l}\text { Cuidado de la } \\
\text { naturaleza }\end{array}$ & Estar dispuesto a proteger la naturaleza \\
\hline & Desafío & Imaginar desafíos que abordar en la naturaleza \\
\hline & Identidad colectiva & Reflexionar sobre la identidad y el patrimonio colectivos a través de la naturaleza \\
\hline & Conexión & Verse a uno mismo conectado con la naturaleza \\
\hline & Investigación & Estudiar e investigar sobre la naturaleza \\
\hline & Inspiración & Encontrar ideas en la naturaleza \\
\hline & Naturalidad & Apreciar la pureza y tranquilidad de la naturaleza \\
\hline & Perfección & Considerar que la naturaleza es perfecta \\
\hline & Riesgo & Percibir los riesgos y peligros en la naturaleza \\
\hline & Autoconciencia & Reflexionar sobre uno mismo mientras se está en la naturaleza \\
\hline & Sentido del lugar & Pensar sobre el significado, la conexión y la pertenencia a un lugar \\
\hline & Relaciones sociales & Pensar en las relaciones sociales en la naturaleza \\
\hline & Espiritualidad & $\begin{array}{l}\text { Buscar en la naturaleza el significado de la vida o una conexión con algo más } \\
\text { grande que uno }\end{array}$ \\
\hline & Utilidad e intervención & $\begin{array}{l}\text { Reconocer los beneficios que brinda la naturaleza y el dominio de los seres } \\
\text { humanos sobre ella }\end{array}$ \\
\hline
\end{tabular}

\section{Afectiva}

\begin{tabular}{ll}
\hline Apreciación & Experimentar fascinación y asombro, estar agradecido, sentir orgullo \\
\hline Temor & Experimentar miedo, asustarse \\
\hline Tranquilidad de espíritu & Sentirse esperanzado, libre y tranquilo \\
\hline Placer & Sentirse feliz y satisfecho, experimentar alegría, estar eufórico, sentir amor \\
\hline Tristeza & Sentirse triste \\
\hline
\end{tabular}


mientras que las actividades fueron mencionadas con menor frecuencia (30\%). El sentido de la vista fue el sentido mencionado con mayor frecuencia. Encontramos una gran diversidad de experiencias cognitivas (tabla 1), de las cuales la más frecuente fue la conexión con la naturaleza. La tranquilidad fue la categoría más frecuente entre las experiencias afectivas.

La mayoría de las descripciones de imágenes (81\%) incluían una experiencia afectiva o sensorial, o ambas. Únicamente el 21 \% de las descripciones de imágenes informaron solo sobre una de las tres experiencias (figura 3).

Nos sorprendieron las muchas emociones y

sentimientos profundos que compartieron los entrevistados.

"El cañón, las formas geológicas, el agua, los espacios llenos de aguas termales, las estalagmitas y estalactitas, las plantas: todo es maravilloso en este lugar. Es un placer absoluto. Suelo ir de noche, cuando no hay nadie. Puedes ver las estrellas. Es el contacto más fuerte que he tenido. El sonido del río es como una música que llega a tu corazón. Aunque uno de mis amigos murió allí, me transmite un miedo y una alegría estar en medio del cañón".

También nos sorprendió la gran diversidad de experiencias sensoriales, dado que el estímulo visual involucró fotografías. Aunque la experiencia sensorial

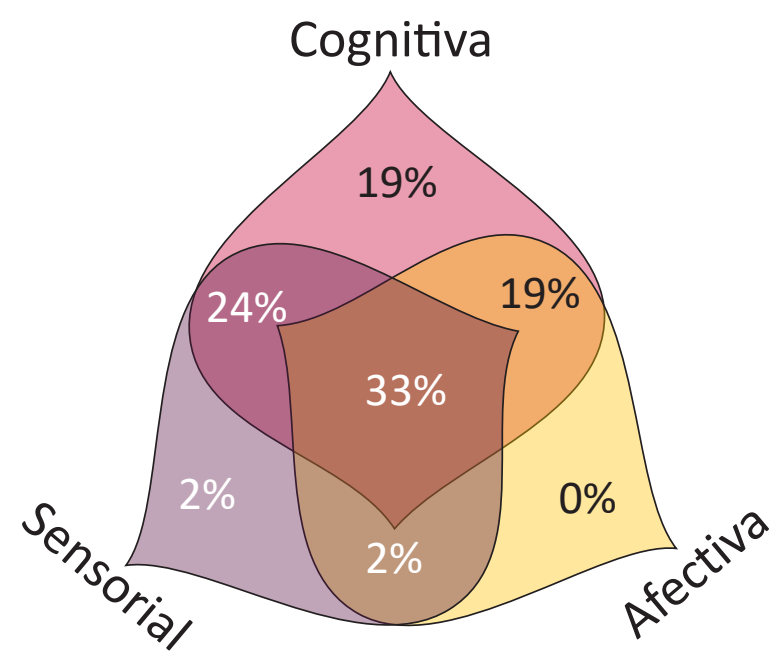

Figura 3. Diagrama de Venn que muestra la proporción de descripciones de imágenes que informan sobre una experiencia sensorial, cognitiva o afectiva. predominante era visual, la gente hablaba sobre el tacto, el oído, el sentido del movimiento y la gravedad.

"Me gusta el olor de la tierra húmeda y las hierbas aromáticas. Me gusta sentir la humedad del bosque. Me gusta escuchar el sonido de los pájaros, los insectos, mis pasos o el clic de la cámara".

En lo que respecta a la dimensión cognitiva, las reflexiones sobre la conexión con la naturaleza y el lugar fueron comunes en las narrativas. Además, las experiencias sensoriales y afectivas compartidas por los participantes implican conectividad con la naturaleza y el lugar, ya que sin ellas la conectividad rara vez se da.

"El agua, el cielo y las montañas me recuerdan lugares similares en otros ecosistemas de alta montaña. Desde mi experiencia de vida, estoy conectado con este tipo de paisaje".

La paz mental, o sentirse tranquilo y reconfortantemente apacible, fue una experiencia afectiva compartida con frecuencia.

"Me gusta cuando el agua está algo verdosa y calmada. Me gustan el sonido del río y su color, con las rocas y el viento. Los ríos se llevan todo lo que no quieres. Me relaja mucho y eso me gusta".

\section{Tomar en cuenta la equidad}

Al igual que con todos los servicios de los ecosistemas, las contribuciones no materiales de la naturaleza (y las experiencias cognitivas, sensoriales y afectivas asociadas que son importantes para el bienestar humano y el comportamiento conservacionista) no son accesibles de manera equitativa para todas las personas. Las capacidades físicas y financieras, la accesibilidad, las habilidades y el conocimiento, los derechos percibidos, la confianza, el contexto social y las condiciones ambientales influyen en lo que las personas pueden hacer, ser y experimentar.

La reciente Evaluación Global de la Plataforma Intergubernamental Científico-Normativa sobre Biodiversidad y Servicios de los Ecosistemas (IPBES) muestra una marcada división entre las personas que pueden captar las contribuciones no materiales de la naturaleza y las que no (Brauman et al. 2020). Por ejemplo, el interés y la capacidad de participar en el turismo de naturaleza se ha incrementado para los residentes urbanos más ricos, mientras que el cambio de uso de la tierra y la migración del campo a la ciudad ha significado que la exposición de la gente pobre a la naturaleza ha 
disminuido, lo que ha llevado a pérdidas de identidad y de experiencia directa.

Un estudio de comunidades dependientes de los recursos naturales en Chile encontró que las comunidades rurales que dependen de los bienes (o contribuciones materiales) de los ecosistemas para su sustento y pasan mucho tiempo en la naturaleza aprecian el aire libre como un lugar que satisface necesidades importantes que van más allá de lo material (Elwell et al. 2020). En cambio, las personas asalariadas apreciaron las contribuciones de los ecosistemas al bienestar, pero menos que las comunidades que dependen de los recursos. Esto podría deberse a que se sintieron menos capaces de acceder a los ecosistemas para satisfacer tales necesidades o porque pasaron menos tiempo en la naturaleza $y$, por lo tanto, no experimentaron directamente los ecosistemas como lugares espirituales o recreativos

Un estudio realizado en Kenia halló resultados opuestos. Las comunidades rurales en aldeas remotas y los asentamientos de pastores estaban menos conectados emocionalmente con la naturaleza que las comunidades urbanas (Marczak y Sorokowski 2018). Los autores explicaron estos resultados por los diferentes contextos de interacciones entre los seres humanos y la naturaleza. Los residentes urbanos disfrutaron de paisajes naturales en el contexto del tiempo libre y la recreación, mientras que el contacto constante con la naturaleza de las comunidades rurales remotas estuvo marcado por la presencia de animales salvajes peligrosos, el calor extremo y la escasez de agua en la estación seca, lluvias torrenciales monzónicas y otras dificultades y riesgos.

Estos importantes temas de equidad requieren mayor atención en la gestión de ecosistemas y paisajes para revelar cualquier pérdida pasada y potencial de experiencias vividas directas, identidad y sentido de lugar. Estos problemas pueden volverse particularmente importantes para la gestión de ecosistemas relacionados con la conservación y/o el ecoturismo.

\section{Hacia una gobernanza inclusiva}

Los servicios culturales de los ecosistemas están situados en lugares, y cualquier acción que afecte a dichos lugares (incluida la forma en que las personas los experimentan e interpretan) afecta también el bienestar. Tales acciones pueden ser una fuente de justicia o injusticias. El ecoturismo, un ejemplo popular de servicios culturales de los ecosistemas, puede afectar el sentido del lugar y las relaciones entre el ser humano y la naturaleza mediante la creación de marcas y el desarrollo o creación de lugares (place-making), o a través de instituciones poderosas que establecen significados y normas al paisaje. Las iniciativas de conservación pueden producir trayectorias similares.

El desarrollo o creación de lugares ocurre cuando se asignan sensaciones y emociones a lugares particulares y se priorizan interacciones específicas entre personas y paisajes (mientras se ocultan otras interacciones y prácticas, en especial las de los habitantes locales). Esto puede llevar a negociaciones difíciles y desiguales sobre la gestión del paisaje y los ecosistemas. Incorporar la diversidad de las experiencias vividas por las personas sobre el lugar y la naturaleza (sensoriales, emocionales, cognitivas) en las decisiones sobre el uso de la tierra puede conducir a una gestión del paisaje más inclusiva y a mejores resultados de conservación y para el bienestar humano.

\section{Mejora de las intervenciones y la accesibilidad}

Las sensaciones y las emociones son mecanismos básicos a través de los cuales las personas se conectan con los ecosistemas y la naturaleza, y deben ser valorados junto con las formas más cognitivas de relacionarse con los ecosistemas. Diferentes sensaciones y emociones, así como valores, creencias y actitudes, todo influye en los vínculos entre los ecosistemas, el bienestar humano, la conectividad con la naturaleza y el lugar, y el comportamiento ambientalmente responsable (el cual es a su vez mejorado por la conectividad) (Zylstra et al. 2014; Frumkin et al. 2017).

\section{El involucramiento sensorial es un prerrequisito} para que surjan estados afectivos y cognitivos positivos, así como para la conectividad. No es suficiente que las personas pasen tiempo en la naturaleza; también necesitan notar y apreciar la naturaleza para desarrollar conectividad y darse cuenta de los beneficios fisiológicos, psicológicos y sociales. Los administradores de ecosistemas pueden fomentar ese involucramiento y hacerlo más accesible.

A escala local, incluso las intervenciones pequeñas pueden ayudar a mejorar la accesibilidad. Estas pueden ser, por ejemplo, cercos vivos de árboles y arbustos nativos, huertos forestales comestibles, infraestructura sencilla como una banca que ayude a destacar un mirador y otras estímulos o señales para el involucramiento sensorial, emocional y cognitivo (Elwell et al. 2020). Tales 
intervenciones han estado apareciendo en áreas urbanas, pero queda aún mucho por hacer para garantizar el acceso de personas con diferentes capacidades y de diferentes orígenes socioeconómicos.

Comprender por qué, cómo y cuándo las personas se dan cuenta y se involucran con la naturaleza y los ecosistemas puede ser útil para diseñar y evaluar tales intervenciones. Explorar las diferencias en las experiencias y los imaginarios en función de las características sociodemográficas, las condiciones sociales y ambientales, las actividades, las capacidades personales, los valores o el tiempo pasado en la naturaleza son temas importantes para futuras investigaciones. Las investigaciones futuras también pueden examinar diferentes contribuciones de la naturaleza al bienestar y su importancia percibida frente a estas características y factores contextuales diferenciadores.

\section{Recomendaciones}

- Los responsables de la toma de decisiones deben fomentar una toma de decisiones más deliberativa y participativa. Se pueden utilizar herramientas como la evaluación multicriterio social (EMS) para comparar y discutir alternativas de uso del suelo frente a múltiples criterios e indicadores subjetivos de bienestar que reflejan las experiencias vividas, los imaginarios y los valores de diversos actores.

- El enfoque biocultural hacia la conservación y la gestión de los ecosistemas (que pone énfasis en las prácticas culturales que influyen y son influenciadas por los paisajes terrestres y marinos) es otro enfoque útil para incorporar diversas experiencias, interacciones y valores de la relación entre el ser humano y la naturaleza.

- La planificación y las intervenciones del paisaje también podrían centrarse en fomentar el compromiso sensorial y afectivo con la naturaleza, al mismo tiempo que se consideran las capacidades de diferentes grupos y se mejora la accesibilidad de las contribuciones no materiales de la naturaleza al bienestar humano.

- Los conjuntos de herramientas y lineamientos, como las "5 formas de estar más cerca de la naturaleza" del National Trust y la Universidad de Derby en el Reino Unido (Richardson 2017), se pueden modificar y adaptar para adecuarlos también a los contextos de países no occidentales.

- La investigación cualitativa con un enfoque mínimo en los problemas puede aportar importantes conocimientos hacia estos objetivos y potencialmente dar voz a grupos y experiencias marginados.

\section{Agradecimientos}

Este artículo es una contribución de la Transformative Adaptation Research Alliance (TARA, https://research. csiro.au/tara/), una red internacional de investigadores y profesionales dedicados al desarrollo e implementación de enfoques novedosos para la adaptación transformadora al cambio global. Los socios financiadores que han apoyado esta investigación incluyen la Iniciativa Climática Internacional (IKI, proyecto 15_III_075) del Ministerio Federal Alemán de Medio Ambiente, Conservación de la Naturaleza, Construcción y Seguridad Nuclear (BMUB); la Agencia Noruega de Cooperación al Desarrollo (acuerdo QZA-016/0110); el programa de investigación e innovación H2020 de la Unión Europea (Proyecto SINCERE); el Ministerio francés para la Transición Ecológica e Inclusiva; y el Programa de Investigación del CGIAR sobre Bosques, Árboles y Agroforestería (CRP FTA) con apoyo financiero del Fondo CGIAR. Los autores agradecen a Helvetas, el Programa Bosques Andinos, el Centro de Estudios y Desarrollo Social (CEDES) y el Instituto de Desarrollo y Medio Ambiente (IDMA) por su apoyo en la organización del trabajo de campo. Los autores agradecen a todos los entrevistados por su tiempo y valiosa información, y a los revisores anónimos por sus útiles comentarios.

\section{Referencias}

Arguedas JM. 1958. Los ríos profundos. Buenos Aires, Argentina: Losada S.A.

Brauman KA, Garibaldi LA, Polasky S, Aumeeruddy-Thomas Y, Brancalion PHS, DeClerck F, Jacob U, Mastrangelo ME, Nkongolo NV, Palang H, et al. 2020. Global trends in nature's contributions to people. Proceedings of the National Academy of Sciences 117(51): 32799-32805.

Elwell TL, López-Carr D, Gelcich S, Gaines SD. 2020. The importance of cultural ecosystem services in natural resource-dependent communities: Implications for management. Ecosystem Services 44: 101123.

Fish R, Church A, Winter M. 2016. Conceptualising cultural ecosystem services: A novel framework for research and critical engagement. Ecosystem Services 21: 208-217.

Frumkin H, Bratman GN, Breslow SJ, Cochran B, Kahn PH Jr, Lawler JH, Levin PS, Tandon PS, Varanasi U, Wolf KL, et al. 2017. Nature contact and human health: A research agenda. Environmental Health Perspectives 125(7): 075001.

Locatelli B, Lavorel S, Sloan S, Tappeiner U, Geneletti D. 2017. Characteristic trajectories of ecosystem services in mountains. Frontiers in Ecology and the Environment 15(3): 150-159.

Mastrángelo ME, Pérez-Harguindeguy N, Enrico L, Bennett E, Lavorel S, Cumming GS, Abeygunawardane D, Amarilla LD, Burkhard B, Egoh BN, et al. 2019. Key knowledge gaps to achieve global sustainability goals. Nature Sustainability 2: 1115-1121. 
Marczak M, Sorokowski P. 2018. Emotional connectedness to nature Is meaningfully related to modernization. Evidence from the Meru of Kenya. Frontiers in Psychology 9: 1789.

Pramova E, Locatelli B, Valdivia-Díaz M, Vallet A, Quispe Conde Y, Djoudi H, Colloff MJ, Bousquet F, Tassin J, Munera Roldan C. 2021. Sensing, feeling, thinking: relating to nature with the body, heart and mind. People and Nature. https://doi.org/10.1002/pan3.10286

Richardson M. 18 de mayo de 2017. 5 ways to be closer to nature [blog]. University of Derby, Reino Unido. Fecha de acceso: 19 de octubre de 2021. https://www.derby. ac.uk/blog/5-ways-closer-nature/
Vallet A, Locatelli B, Barnaud C, Makowski D, Quispe Conde Y, Levrel H. 2020. Power asymmetries in social networks of ecosystem services governance. Environmental Science and Policy 114: 329-340.

Vallet A, Locatelli B, Levrel H, Dendoncker N, Barnaud C, Quispe Conde Y. 2019. Linking equity, power, and stakeholders' roles in relation to ecosystem services. Ecology and Society 24(2): 14.

Zylstra MJ, Knight AT, Esler KJ, Le Grange LLL. 2014. Connectedness as a core conservation concern: An interdisciplinary review of theory and a call for practice. Springer Science Reviews 2(1-2): 119-143.

Este trabajo ha sido desarrollado como parte de la plataforma GENDER del CGIAR, que agradece el apoyo Platform de los Contribuyentes del Fondo Fiduciario del CGIAR. www.cgiar.org/funders investigación para el desarrollo más grande del mundo dedicado a destacar el papel de los bosques, los árboles y la agroforestería para el desarrollo sostenible, la seguridad alimentaria, y frente al cambio climático. CIFOR dirige el programa FTA en asociación con ICRAF, la Alianza Bioversity International-CIAT, CATIE, CIRAD, INBAR y TBI.

La investigación del Programa FTA cuenta con el apoyo del Fondo Fiduciario del CGIAR: cgiar.org/ funders

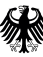

Federal Ministry for the Environment, Nature Conservation and Nuclear Safety

\section{Norad}

\section{cifor-icraf.org}

\section{CIFOR-ICRAF}

El Centro para la Investigación Forestal Internacional (CIFOR) y el Centro Internacional de Investigación Agroforestal (ICRAF) conciben un mundo más equitativo donde los árboles en todos los paisajes, desde las tierras áridas hasta los trópicos húmedos, contribuyen a mejorar el medioambiente y bienestar de todos y todas. CIFOR-ICRAF son centros de investigación del CGIAR.

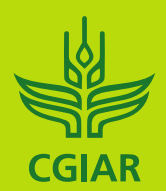

